\title{
Pengaruh Locus of Control Dan Stres Kerja Terhadap Kinerja Dosen Akademi Kebidanan
}

\author{
Anah Sugihanawati ${ }^{1}$ \\ ${ }^{I}$ STIK budi kemuliaan, Gambir. Jakarta. 10110. Indonesia
}

\begin{tabular}{l}
\hline ARTICLE INFORMATION \\
\hline Article Trace \\
Submission: August, 14, 2019 \\
Final Revision: September 19, 2019 \\
Available online: October 26, 2019 \\
\hline
\end{tabular}

\section{Kata Kunci :}

Locus of control, stress kerja, kinerja

Key Word :

locus of control, works stress, performance

Contact:

anahsugihanawati@gmail.com

\begin{abstract}
A B S T R A C T
Bidan professional dihasilkan dari pendidikan bidan yang baik. Pendidikan bidan yang baik membutuhkan pembimbing atau dosen yang baik. Beberapa data ditemukan bahwa kinerja dosen pada akademi kebidanan di Indonesia masih menjadi tantangan terutama kinerja secara umum ataupun kinerja khusus dalam menjalankan tridarma perguruan tinggi. Penelitian ini ingin mengetahui pengaruh locus of control dan stres kerja terhadap kinerja. Penelitian ini adalah penelitian kuantitatif dengan metode survey analisis pada 108 dosen akademi kebidanan di wilayah DKI Jakarta. Responden dipilih secara acak / random. Statistik inferensial digunakan untuk menguji hipotesis tentang pengaruh antar variabel dengan menggunakan tehnik analisis jalur. Hasil Penelitian menunjukkan bahwa Locus of control adalah efek positif langsung terhadap kinerja; Stres kerja merupakan efek negatif langsung terhadap kinerja,dan Locus of control berpengaruh langsung negatif terhadap stres kerja. Hasil penelitian dapat membantu dalam meningkatkan kinerja melalui peningkatan locus of control dan menurunkan stress kerja pada dosen kebidanan.
\end{abstract}

\begin{abstract}
A B S T R A C T
Professional midwives are produced from a good midwives education. Good midwives ' education requires a good mentor or lecturer. Some data were found that the lecturers ' performance in obstetrics academy in indonesia is still a challenge especially in general performance or special performance in conducting high school tridarma. The study wanted to know the effects of locus of control and work stress on performance. This research is a quantitative study with analysis survey method of 108 obstetrician academy lecturers in dki jakarta area. respondents are randomly selected. inferential statistics are used to test hypotheses about the influence between variables using pathway analysis techniques. The results showed that locus of control was a direct positive effect on performance; occupational stress is a direct negative effect on performance, and locus of control directly negatively affects the stress of work. research results can help in improving performance through improved locus control and lower working stress on obstetrics lecturers.
\end{abstract}




\section{PENDAHULUAN}

Dosen merupakan salah satu sumber daya yang memiliki elemen penting dalam organisasi pendidikan dan sebagai tenaga akademisi yang bekerja dalam suatu organisasi lembaga perguruan tinggi, salah satu upaya untuk meningkatkan kualitas institusi pendidikan yaitu melalui peningkatan kinerja dosen dalam melaksanakan Tri Darma Perguruan Tinggi. Dosen bukan sekedar menyampaikan materi perkuliahan, tetapi di tuntut juga untuk melakukan penelitian-penelitian (research) ilmiah dan pengabdian terhadap masyarakat.

Sebagaimana diamanatkan Undang - Undang RI Nomor 14 Tahun 2005 tentang Guru dan Dosen bahwa, dosen adalah pendidik profesional dan ilmuwan dengan tugas utama mentransformasikan, mengembangkan, dan menyebarluaskan ilmu pengetahuan, teknologi dan seni melalui pendidikan, penelitian, dan pengabdian kepada masyarakat. Undang-undang tersebut menjadi landasan yang kuat agar dosen mempunyai kinerja yang baik.

Dari beberapa temuan dapat diketahui penyebab rendahnya kinerja dosen memperlihatkan bahwa keberadaan dosen di wilayah DKI Jakarta belum dapat mengimbangi perkembangan IPTEK dan kurang maksimal dalam pengembangan penelitian dan pengabdian kepada masyarakat di bidang keilmuannya, dalam melaksanakan tugas dan fungsinya sebagai dosen, masih rendah dalam penilaian keyakinan tentang keberhasilan kinerjanya baik dari akibat usahanya sendiri atau pengaruh dari luar. Seperti kurang semangat dalam membuat karya ilmiah dan pengabdian terhadap masyarakat, karena dosen kebidanan juga ada tugas tambahan dalam bidang administrasi sebagai administrator. (naskah akademik system pendidikan bidan, 2014)

Kinerja

Faktor lain yang dapat mempengaruhi kinerja dosen seperti motivasi, job satisfaction, penghargaan, iklim organisasi, kepemimpinan, self efficacy, selfesteem, dan desain kerja sudah harus menjadi perhatian bersama masalah kinerja dosen Akademi Kebidanan. Dari banyak faktor yang mempengaruhi rendahnya kinerja dosen, penelitian ini dibatasi hanya pada

\footnotetext{
*Korespondensi penulis: anahsugihanawati@yahoo.com
}

pengaruh Locus of Control dan stres kerja terhadap kinerja dosen.

Pengertian kinerja (Job Performance) menurut Colquitt, et. all., (2009:37) "job performance is the value of the set of employee behaviors that contribute, either positively or negatively, to organizational goal accomplishment". Kinerja adalah seperangkat darin ilai perilaku pegawai yang berkontribusi secara positif atau negatif untuk mencapai tujuan organisasi.

Kinerja menurut J. Campbell dalam bukunya Steve M. Jax (2002:95), adalah "job performance is determined by the interaction among declarative knowledge, procedural knowledge/skill, and motivation".Kinerja ditentukan oleh interaksi antara pengetahuan umum, pengetahuan prosedural /keterampilan dan motivasi.

Pendapat dari George dan Jones (2012:158), "job performance is an evaluation of the result of a person's behavior: it involves determining how well or poorly a person has accomplished a task or done a job. "Kinerja adalah evaluasi hasil perilaku seseorang: menentukan seberapa baik atau buruk seseorang telah menyelesaikan tugas atau melakukan pekerjaannya. Menurutnya, kinerja seseorang diketahui dengan cara melakukan penilaian terhadap perilaku positif dan perilaku negatifnya dalam hal penyelesaian tugas atau pekerjaan.

\section{Locus of Control}

Menurut Slocum, Hellriegel (2094:44), "locus of control is the extend to which individuals believe that they can control events affecting them". Locusof control adalah individu yakin bahwa mereka dapat mengontrol peristiwa yang mempengaruhi mereka.

Lebih lanjut, pendapat Stephen P. Robbins (2012:159), "locus of control is the degree to which people believe they control their own fate". Locus of control adalah sejauh manaorang meyakini bahwa mereka mengendalikan nasib mereka sendiri.

Pendapat dari Ivan cevich, Konopaske, Matteson, (2008:78), mengungkapkan bahwa locus of control adalah "the locus of control of individuals determines the degree to which they 
believe their behaviors influence what happens to them". Locus of controlseseorang akan menentukan sejauh mana keyakinannya terhadap keberhasilan hidupnya.

Berdasarkan uraian di atas dapat disintesiskan locus of control adalah kendali individu atas kepercayaannya dalam menilai keberhasilan yang diperolah dalam melaksanakan pekerjaannya, dengan indikator yaitu: mempunyai tanggung jawab terhadap pekerjaan, mempunyai kemandirian dalam bekerja, mengatasi tekanan dalam bekerja, dan mempunyai keaktifan dalam bekerja.

\section{Stres Kerja}

Colquitt, et. al., (2009:303), mendefinisikan, "stress is defined as a psychological response to demands for which there". Stres adalah respon psikologis terhadap tuntutanyang ada. Larsen (2010:555), mendefinisikan stres yaitu, "stress is the subjective feeling produced by events that are uncontrollable or threatening. it is important to realize that stress is a response to the perceived demands in some situation". Stres adalah perasaan subjektif yang dihasilkan oleh peristiwa yang tidak terkendali atau mengancam. Hal ini adalah penting untuk menyadari bahwa stres merupakan respon terhadap tuntutan yang dirasakan dalam beberapa situasi.

Pendapat Kreitner dan Kinicki (2011:555),"stress is adaptive response, mediated by individual characteristics and/or psychological processes, that is a consequence of any external action, situation, or event that places special physical and/or psychological demands upon a person".Stres adalah sebuah respon adaptif dari setiap individu yang dipengaruhi oleh karakter dari setiap pribadi atau proses psikologi yang merupakan konsekuensi dari setiap tindakan atau situasi, keadaan dari luar sehingga menyebabkan adanya tuntutan psikologis maupun fisik yang khusus pada seseorang.

Dengan demikian, dari deskripsi konsep di atas dapat disintesiskan stres kerja adalah kondisi seseorang terhadap tanggapan pada tekanan baik dari dalam diri maupun dari lingkungannya, dengan indikator yaitu: gangguan psikologis, gangguan fisiologis, dan gangguan berperilaku

\section{METODE PENELITIAN}

Penelitian ini dilakukan di lima Akademi Kebidanan di wilayah DKI Jakarta, tujuan dari penelitian ini untuk menguji pengaruh langsung; (1) locus of control terhadap kinerja, (2) stres kerja terhadap kinerja, dan (3) locus of controlterhadap stres kerja. Penelitian ini menggunakan metode survey dengan pendekatan teknik analisis jalur dan pelaksanaannya selama empat bulan mulai bulan Agustus s/d November 2014. Populasi dalam penelitian ini sejumlah 108 dosen Akademi Kebidanan Swasta di DKI Jakarta. Sampel yang digunakan dalam penelitian sebanyak 20 orang. Data penelitian didapat dengan menggunakan instrumen. Instrumen yang digunakan adalah Kuesioner/angket yang disebarkan kepada responden.

Analisa data untuk pengujian hipotesis dilakukan dengan menggunakan teknik analisis jalur, yaitu teknik yang diterapkan untuk menjelaskan pengaruh antara variabel-variabel penelitian. Sebelum dilaksanakan analisis jalur, uji signifikan regresi dan uji linearitas regresi sebagai prasyarat uji statistik dilakukan pengujian penormalan data dari masing-masing variabel penelitian dengan Uji-Liliefors, Statistik inferensial digunakan untuk menguji hipotesis tentang pengaruh antar variabel dengan menggunakan tehnik analisis jalur.

\section{HASIL DAN PEMBAHASAN}

\section{Pengaruh Locus of Control terhadap Kinerja}

Dari hasil pengujian hipotesis pertama dapat disimpulkan bahwa terdapat pengaruh langsung positif Locus of control terhadap kinerja dengan nilai koefisien korelasi sebesar 0,323 dan nilai koefisien jalur sebesar 0,253.

Tabel 1. Pengaruh Locus of Control terhadap Kinerja

\begin{tabular}{lcccc}
\hline $\begin{array}{l}\text { Pengaruh } \\
\text { langsung }\end{array}$ & $\begin{array}{c}\text { Koefisien } \\
\text { Jalur }\end{array}$ & $\mathrm{t}_{\text {hitung }}$ & \multicolumn{2}{c}{$\mathrm{t}_{\text {tabel }}$} \\
& $\alpha=0,05$ & $\alpha=0,01$ \\
\hline $\begin{array}{c}\mathrm{X}_{1} \text { terhadap } \\
\mathrm{X}_{3}\end{array}$ & 0,253 & $2,724 * *$ & 1,98 & 2,63 \\
\hline
\end{tabular}

Hal penelitian ini membuktikan adanya pengaruh langsung positif locus of control terhadap kinerja. Hasil penelitian ini relevan 
dengan teori pada gambar The effect of locus of control on performance yang dikemukakan oleh Robbins dan Langton (2008:47), dalam menjelaskan gambar menggunakan pendapat Trump yaitu, "a considerable amount of research has been directed toward relating high and low Mach personalities to certain behavioural outcomes. High Machs manipulate more, win more, are persuaded less, and persuade others more than do low Machs.Think of Donald Trump interacting with the characters on The Apprentice. Yet these high-Mach outcomes are moderated by situational factors. It has been found that high Machs flourish (1) when they interact face to face with others rather than indirectly; (2) when the situation has a minimum number of rules and regulations, thus allowing latitude for improvisation; and (3) when low Machs get distracted by emotional involvement with details irrelevant to winning". Penjelasan Trump ini berdasarkan riset tentang tinggi dan rendah kepribadian seseorang terhadap perilaku yang dilakukan yaitu apabila terjadi interaksi oleh situational faktor. Situasi pertama ketika saling berhubungan secara langsung dengan orang lain secara tidak langsung, situasi kedua, ketika mempunyai suatu jumlah minimum aturan dan peraturan, dan situasi ketiga, ketika keterlibatan emosional yang tidak relevan.

\section{Pengaruh Stres Kerja terhadap Kinerja}

Dari hasil pengujian hipotesis kedua dapat disimpulkan bahwa terdapat pengaruh langsung negatif stres kerja terhadap kinerja dengan nilai koefisien korelasi sebesar $-0,249$ dan nilai koefisien jalur sebesar $-0,320$.

Tabel 2. Pengaruh Stres Kerja terhadap Kinerja

\begin{tabular}{ccccc}
\hline $\begin{array}{c}\text { Pengaruh } \\
\text { langsung }\end{array}$ & $\begin{array}{c}\text { Koefisien } \\
\text { Jalur }\end{array}$ & $\mathrm{t}_{\text {hitung }}$ & \multicolumn{2}{c}{$\mathrm{t}_{\text {tabel }}$} \\
& & & $\alpha=0,05$ & $\alpha=0,01$ \\
\hline $\mathrm{X}_{2}$ terhadap $\mathrm{X}_{3}$ & $-0,249$ & $-2,679 * *$ & $-1,98$ & $-2,63$ \\
\hline
\end{tabular}

Hasil penelitian pada tabel 2 membuktikan adanya pengaruh langsung negatif stres kerja terhadap kinerja. Hasil penelitian ini senada dengan pendapat yang diungkapkan oleh Cohen et. al.,(2010:190) bahwa, "at any stage of life, stress can be a factor affecting performance". Pendapat ini dapat diartikan bahwa, padasetiap tahap kehidupan, stress dapat menjadi faktor yang mempengaruhi kinerja.

\section{Pengaruh Locus of Control terhadap Stres Kerja}

Dari hasil pengujian hipotesis ketiga dapat disimpulkan bahwa terdapat pengaruh langsung negatif locus of control terhadap stres kerjadengan nilai koefisien korelasi sebesar0,279 dan nilai koefisien jalur sebesar -0,279. Ini membuktikan adanya pengaruh langsung negatif locus of control terhadap stres kerja.

Tabel 3. Pengaruh Locus of Control terhadap Stres Kerja

\begin{tabular}{ccccc}
\hline $\begin{array}{c}\text { Pengaruh } \\
\text { langsung }\end{array}$ & $\begin{array}{c}\text { Koefisien } \\
\text { Jalur }\end{array}$ & $\mathrm{t}_{\text {hitung }}$ & \multicolumn{2}{c}{$\mathrm{t}_{\text {tabel }}$} \\
$\alpha=0,05$ & $\alpha=0,01$ \\
\hline $\begin{array}{c}\mathrm{X}_{1} \text { terhadap } \\
\mathrm{X}_{2}\end{array}$ & $-0,279$ & $-2,998 * *$ & $-1,98$ & $-2,63$ \\
\hline
\end{tabular}

Hasil penelitian ini senada dengan pendapat yang dikemukakan oleh Duane dan Ellen Schultz (2006:360-361) bahwa: internal and external locus of control influences a persons reaction to stress. People who rate high on internal control believe thatthey can influence the forces and events that shape their lives. people who rate high on external control believe that life is determined by other people and by outside events and forces such as luck or chance. Pendapat ini dijelaskan bahwa internal dan eksternal locus of control dapat mempengaruhi seseorang terhadap stres. Seseorang yang menilai tinggi pada pengendalian internal percaya bahwa mereka dapat mempengaruhi kekuatan dan peristiwa yang membentuk kehidupan mereka.Seseorang yang menilai tinggi pada kontrol eksternal percaya bahwa hidup ditentukan oleh orang lain dan oleh peristiwa di luar dan kekuatan seperti keberuntungan atau kesempatan. 


\section{KESIMPULAN}

Berdasarkan hasil analisa dan kajian dari penelitian ini dapat disimpulkan bahwa: (1) terdapat pengaruh langsung positif locus of control terhadap kinerja, (2) terdapat pengaruh langsung negatif stres kerja terhadap kinerja, dan (3) terdapat pengaruh langsung negatif locus of control dengan stres kerja.

\section{DAFTAR PUSTAKA}

Allan R. Cohen, at.all. Effective Behavior in OrganizationCases, Concepts, and Student Experience.New York: McGrawHill,Irwin, 2010.

Colquitt, Jason A, Jeffery A. Le Pine, and Michael J.Wesson, Organizational Behavior. New York: McGraw-Hill/Irwin, 2009.

Danang Sunyoto.Perikau Organisasional. Jakarta: CAPS, 2013.

Don Hellriegel, Jhon W. Slocum, Jr., Organizational Behavior, Tenth Edition. Canada:Thomson, 2004.

Duane Schultz dan Sydney Ellen Schultz, Psychologi \& Work Today, Pearson International Edition.Canada: Pearsen Prentince Hall, 2006.

Fred Luthans, Organizational Behavior, An Evidance-BasedAproach, Twelfth Edition. New York: McGraw Hill, Irwin, 2011.

Ivancevich, Konopaske, Matteson, Organizational Behavior and Management, eighth edition.Singapore: McGraw-Hill International, 2008.

James L. Gibson, Jhon M. Ivancevich, James H. Donnely, Robert Konopaske. Organizations Behavior Structure. New York: McGraw-Hill, 2006.

Jennifer M. George, Gareth R. Jones. Understanding and Managing Organizational Behavior $6^{\text {th }}$ Edition.New Jersey: Pearson Edication, 2012.

John R. Schermerhorn. Jr, James G. Hunt, Richad N. Obsorn, Organizational Behavior, Ninth Edition. America: Wiley John \& Sons, Inc, 2005.
John W. Slocum, Hellriegel, Principles of Organizational Behavior, Twelfth Edition. China: South-Western Cengange Learning, 2009.

Journal of Bussines and Social Science, Vol. 2, No 18, 2011.

Journal of Stress Management, 10725245/00/0700-0209, Vol. 7, No. 3, 2000.

Journal Leadership \& Organization Development, $\quad$ Doi 10.1108/01437730810906326, Vol. 29 No. 7, 2008.

Kompas, RisetDosen Lebih Banyak untuk Kenaikan Pangkat, 6 Februari 2014.

Mary Uhl-Bien, John R. Schermerhorn and Richard N. Osborn, Organizational Behavior $13^{\text {th }}$ Edition. USA: Wiley, 2014.

McShane, L Steven, Marry Ann Von Glinow, Organizational Behavior, Emerging Realities for the Workplace Revolution. McGraw-Hill, International Edition, 2005.

Nancy Langton, Stephen Robbin. Fundamental of Organizational Behaviour. Canada: McGraw-Hill, 2008.

Robbins, P Stephen, Timothy A.Judge. Organizational Behavior, fourteenth Edition. England: Pearson, 2011.

Steve M. Jax. Organizational Psychology.A Scientes-Practitioner Approach. New York: John Wiley, INC, 2002.

Sugiono.Metodologi Penelitian Kuantitatif Kualitatif dan $R \& D$. Bandung: Alfabeta, 2013.

Undang-Undang RI No. 14. Tentang Guru dan Dosen. Jakarta:Asa Mandiri, 2006.

Walter C. Borman, at al.Hand Book of Psychology: Industrial and Organizational Psychology. New Jersey: John Wilwy and Son, 2003.

Internet :

http://www.republika.co.id/berita/pendidikan/du nia-kampus/14/02/13/n0x3ai-dosenpeneliti-sering-sekedar-kejarpangkat(diakses 13 Maret 2014).

http://www.hpeq.dikti.co.id,Naskah Akademik Sistem Pendidikan Kebidanan di Indonesia (Jakarta: IBI dan AIPKIND, 2012), h.30. (di akses 15 Februari 2014). 